\title{
Reintegrative Shaming, Procedural Justice, and Recidivism: The Engagement of Offenders' Psychological Mechanisms in the Canberra RISE Drinking-and-Driving Experiment
}

\author{
Tom R. Tyler \\ Lawrence Sherman \\ Heather Strang \\ Geoffrey C. Barnes \\ Daniel Woods
}

\begin{abstract}
Advocates of restorative justice (RJ) hypothesize that the diversion of criminal cases to RJ conferences should be more effective in lowering the rate of reoffending than traditional prosecution in court processing because the conferences more effectively engage the psychological mechanisms of reintegrative shaming and procedural justice. This study uses longitudinal data from the drinking-and-driving study in the Australian Reintegrative Shaming Experiments (RISE) to evaluate the long-term impact of reintegrative shaming and procedural justice on support for the law and on later recidivism as assessed through the use of police records and by self-report. Analysis first suggests that there is no direct effect of experimental condition on later recidivism. However, it further suggests that both traditional court-based prosecution and $\mathrm{RJ}$ conferences increase support for the law and lower the rate of future reoffending when they engage the social psychological mechanisms of reintegrative shaming and procedural justice and thereby increase the legitimacy of the law. Hence, the results argue for the potential value of procedures such as the RJ conference but indicate that those procedures will only achieve their objectives if they are effectively designed and implemented.
\end{abstract}

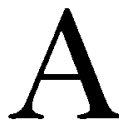

core issue for legal authorities is better understanding how to bring people's behavior into compliance with the law (Tyler $2003,2006 a, 2006 \mathrm{~b})$. In an ideal society the issue of responding to rule-breaking would never arise, but societies never achieve this ideal and must often confront the question of how to deal with offenders and with the consequences of offending behavior. Lawbreaking confronts society with a number of issues, including how to constructively manage offenders who, after they are punished, might reoffend in the future. This article is concerned with the

Please address correspondence to Tom Tyler, Department of Psychology, New York University, 6 Washington Place, Room 579, New York, NY 10003; e-mail: tom.tyler@ nyu.edu.

Law E Society Review, Volume 41, Number 3 (2007)

(C) 2007 by The Law and Society Association. All rights reserved. 
issue of how to deal with offenders so as to increase support for the law and lower the rate of subsequent reoffending.

One approach to lowering reoffending rates is to punish wrongdoers. Punishment incapacitates those who have broken the law during the time that they are in custody, inflicts the costs of punishment on them, and may instill fear of future punishment in them and in others. Deterrence-based strategies are the most common means used within the United States to decrease recidivism. Those strategies have been widely used and are often found to shape behavior (Nagin 1998), although their use has disadvantages, including that deterrence effects are often small (MacCoun 1993), that deterrence systems are costly to maintain, that they undermine the relationship between legal authorities and the public, and that they do not rehabilitate criminals, leading to high levels of recidivism (Luna 2003).

The problems associated with deterrence strategies are well known. However, it is not clear that more effective alternatives exist. In particular, rehabilitation, once thought to be the most important response to criminal behavior, has been argued to be ineffective (Allen 1981) and is unpopular among many public policy makers. If criminals cannot be rehabilitated, then the threat of punishment is often said, by default, to be the primary manner in which societies must maintain social order.

This study tests the effectiveness of two social psychological mechanisms for reducing recidivism: procedural justice and reintegrative shaming. Theory underpinning each of these mechanisms suggests that there are ways to respond to wrongdoing that increase offenders' support for and likelihood of future compliance with the law.

While many types of experience could potentially activate these psychological mechanisms, both have been linked to the use of restorative justice $(\mathrm{RJ})$ conferences in lieu of prosecution through the courts. In such conferences offenders meet with the victim in the company of their friends and family and other interested parties, in the presence of a trained facilitator. Rather than focusing only on the appropriate punishment for past wrongdoing, as occurs in court, RJ conferences confront offenders with the consequences of their actions and encourage them to take personal responsibility for following the law in the future.

\section{The Social Psychological Mechanisms Underlying Effective Legal Procedures}

One reason that $\mathrm{RJ}$ conferences are suggested to be effective in lowering reoffending is via the mechanism of reintegrative shaming 
(J. Braithwaite 1989, 2002; Strang \& Braithwaite 2000), through which offenders reconnect with positive aspects of themselves and ties to significant others in their lives while also recognizing the inappropriateness of their past conduct (also see Ahmed et al. 2001; Johnstone 2002; Roche 2003; Sullivan \& Tifft 2001; Von Hirsch et al. 2003; Weitekamp \& Kerner 2002). This reintegration with the social ties within which they live creates a set of interpersonal expectations that they are committed to following into the future.

$\mathrm{RJ}$ conferences are designed to allow offenders to reconnect with important others in their lives. By seeing that they are respected and loved by people whom they in turn respect and love, and who condemn their bad behavior but do not view them as a bad person, offenders reestablish links to important significant others (Ahmed et al. 2001). Both their desire to maintain those links and to maintain a favorable sense of self motivate offenders not to reoffend. While the development of such connections is a psychological mechanism, it is important to recognize that the arguments of $\mathrm{RJ}$ theory are rooted in sociological theories about the value of social ties to others (i.e., family, friends, community, etc.; see J. Braithwaite 1989, 2002). These mechanisms are complex, and this study draws upon one particular operationalization of reintegrative shaming: that used by Ahmed and colleagues (2001).

Are $\mathrm{RJ}$ conferences effective in lowering subsequent reoffending? It is clear in prior studies that $\mathrm{RJ}$ conferences have a more positive impact upon a number of psychological characteristics than prosecution through the court, including offenders' belief that the criminal justice system is fair, offenders' satisfaction with the handling of the case, offenders' belief that they had the opportunity to tell their side of the story, offenders' belief that their opinion was adequately considered, offenders' belief that the judge/facilitator was fair, and offenders' belief that the law is legitimate and should be obeyed (Barnes 1999). In addition, other parties are more likely to emerge from the procedure feeling that offenders were held accountable, with participants feeling that an apology was offered or forgiveness expressed, and with participants feeling that the outcome was fair, that the outcome was satisfactory, and that the other parties' behavior has improved. Finally, victims emerge less upset at the crime and less afraid of revictimization (Barnes 1999; Poulson 2003; Strang 2002).

What is the evidence concerning whether these many positive psychological outcomes lead to changes in long-term law-related behavior? Nugent and colleagues (2003) review 19 studies exploring the influence of victim-offender mediation (VOM) sessions and subsequent reoffending among juveniles during the one-year period following the session. Their cautious conclusion is that the results "are consistent with the intriguing possibility that VOM 
participation may cause a decrease in delinquent behavior" (2003:162) and that the decrease "may be as great as 26 percent" (2003:162). This review does not, however, explore the psychological mechanisms by which these effects occur. This finding also does not address whether decreases in reoffending may also be found among adults (Poulson 2003).

Latimer and colleagues (2005) directly examine evidence concerning the impact of $\mathrm{RJ}$ on recidivism in adults. They conclude that in approximately $2 / 3$ of the programs studied, $\mathrm{RJ}$ programs "yielded reductions in recidivism compared to nonrestorative approaches to criminal behavior" (2005:137), a difference which they find statistically significant ( $(31)=2.88, p<0.01$ ). Similar results are obtained by Bonta and colleagues (2006). Again, however, these authors do not examine the psychological mechanisms by which these effects occur, nor do they limit their review to randomized controlled trials. When reviews are limited to true experiments, the evidence is more mixed, suggesting either that there is no effect or that, in some cases, the effects may be negative -i.e., conferences may increase recidivism, relative to the influence of court processing (Strang \& Sherman 2006).

Hence, there is some evidence suggesting that $\mathrm{RJ}$ can lead to long-term decreases in offending. Further, reintegrative shaming theory suggests that these changes occur because those who experience reintegrative shaming strengthen their ties to others. As a consequence, they view future rule-breaking as creating greater interpersonal problems for themselves. This model suggests that legal procedures such as $\mathrm{RJ}$ conferences will be more effective in lowering reoffending rates when they successfully engage the psychological mechanisms outlined.

A second reason that $\mathrm{RJ}$ conferences are predicted to lead to long-term compliance is that they are evaluated by offenders as procedurally fair ways to deal with their transgressions. Procedural justice theories argue that experiencing fair procedures leads offenders to view the law and legal authorities as legitimate, leading to enhanced commitment to obey the law. This procedural justice argument is widely supported in studies of the willingness to accept decisions made by legal authorities (Tyler 2000, 2003, 2006a, 2006b; Tyler \& Huo 2002). Sherman (1993) has similarly suggested that informal case processing reduces defiance of and resistance to conventional rules.

$\mathrm{RJ}$ conferences have the capacity to display many of the features associated with procedural justice (Barnes 1999). They allow opportunities to participate by stating one's case and having influence over how the case is resolved. They allow people to see that decisions are being made in ways consistent with rules and without bias. They allow offenders to evaluate the trustworthiness of 
authorities and give authorities the opportunity to communicate respect for offenders as people and for their rights (for an elaboration of these aspects of procedural justice, see Tyler 1988, 2000; Tyler \& Lind 1992). In other words, effective RJ conferences should be experienced by offenders as being procedurally just.

The importance of procedural justice was first demonstrated by Thibaut, a psychologist, and Walker, a lawyer, in a series of laboratory studies on simulated trials (Thibaut \& Walker 1975). Subsequently a large literature has developed demonstrating that procedural justice shapes decision acceptance (Colquitt et al. 2001; Tyler 2000; Tyler \& Huo 2002) and rule-following (Sunshine \& Tyler 2003; Tyler 2006a). Soon after the publication of Thibaut and Walker's summary of their research (Thibaut \& Walker 1975), that work was critiqued for its relevance to real-world behavior (Anderson \& Hayden 1980-81). Since that time a number of efforts have been made to demonstrate the external validity of these findings.

In studies conducted in real-world settings, procedural justice has been found to be linked to self-reported decision acceptance (Tyler \& Huo 2002) and compliance with the law (Tyler 2006a; Sunshine \& Tyler 2003). Further, it has been shown that procedural justice influences independently recorded long-term behavior. It does so following mediation sessions (Pruitt et al. 1993) and police interventions in response to spousal abuse complaints (Paternoster et al. 1997).

Offenders are predicted to be less likely to reoffend when the psychological processes associated with procedural justice are activated. When people experience just treatment by authorities, they are predicted to increase their beliefs that the law is legitimate and ought to be obeyed. These beliefs, in turn, are predicted to motivate compliance with the law. Again, this psychological model predicts that legal procedures will lower subsequent rates of offending when the psychological process of procedural justice is activated.

\section{The RISE Experiments}

The Australian Reintegrative Shaming Experiments (RISE) are a major effort to conduct an experimental evaluation of the effectiveness of diversionary RJ conferences on repeat offending. They consist of four separate experiments: adult drinking and driving, juvenile personal property crime, juvenile shoplifting from large stores, and violent crime committed by offenders up to age 29 . The goal of this article is to provide a test of the power of procedural justice and reintegrative shaming by linking them to later support for the law, to subsequent self-reported behavior, and to reoffending as recorded in police records. It uses longitudinal data 
focusing upon the use of $\mathrm{RJ}$ conferences and court cases to dispose of 900 cases of drinking and driving over the statutory limit (Sherman et al. 2000).

As in all the RISE field tests, offenders were randomly assigned to either be prosecuted and receive traditional courtroom adjudication for this offense or have their cases handled via a RJ conference. This analysis, however, does not focus only on the main effects of the randomized experiment, which did not demonstrate statistically significant lower rates of reoffending in the group randomly assigned to RJ conferences. It also employs the substantial data on each case gathered in the drinking-and-driving experiment in order to examine the long-term influence of the procedure offenders experienced upon their later law-related attitudes and drinking-and-driving behavior.

\section{Psychological Mechanisms}

The key psychological hypothesis to be tested is that, when the psychological processes of either procedural justice or reintegrative shaming are effectively engaged, people develop values that support long-term compliance with the law. Those values are the belief that reoffending would create interpersonal problems in one's relationships with others and the judgment that the law is legitimate and ought to be obeyed. Offenders then become more supportive of the law and less likely to reoffend.

This hypothesis is tested using three types of data about the post-treatment behavior of offenders: (1) self-reports of efforts to follow the law two years after the case disposition by conference or prosecution; (2) self-reports of drinking-and-driving behavior during the two years following case disposition by conference or prosecution; and (3) police records of rearrest during the four-year period following case disposition by conference or prosecution. These police records indicate whether people were arrested for reoffending both during the two-year period prior to the second interview (Years 1-2), and during the two-year period following the second interview (Years 3-4). ${ }^{1}$

\section{RJ Conferences}

Our experimental hypothesis is that conferences will be more effective in creating the feelings of procedural justice and reintegrative shaming than will traditional prosecutions. These dynamics,

1 Rearrest is probably a good indication that people have reoffended, but it is important to remember that people may have reoffended without being detected and rearrested. 
when activated, will then motivate both support for the law and future compliance behavior. Hence, it is hypothesized that enacting procedures that are experienced as procedurally just and that encourage reintegrative shaming will lead to long-term decreases in reoffending behavior.

This study first focuses on the overall difference between the groups randomly assigned to prosecution or diversion to $\mathrm{RJ}$ conferences. It then explores the consequences of the psychological processes activated by prosecution through the courts and $\mathrm{RJ}$ conferences that the participants were involved in as part of this study. It examines whether the processes of procedural justice and reintegrative shaming, once activated by these procedures, shape subsequent beliefs and behavior. This examination of the consequences of the psychological processes resulting from legal procedures is the distinct contribution of this article, which builds upon prior efforts to explore the impact of the experimental treatments upon reoffending (Sherman \& Strang 2004).

In recent years, worldwide support for the use of $\mathrm{RJ}$ conferences has increased strikingly (Roberts \& Stalans 2004). The widespread advocacy of this alternative legal procedure is fueled by dissatisfaction with the traditional court system, which is widely viewed as unsuccessful in lowering high rates of recidivism. However, the long-term success of this movement may depend upon the demonstration that, in fact, $\mathrm{RJ}$ is shaping the psychological motivations that lead to compliance with the law over time among offenders. This study directly addresses this issue.

Second, this study examines the role of the legal procedure experienced in shaping the two psychological mechanisms outlined - reintegrative shaming and procedural justice - and through these psychological processes influencing subsequent support for the law and recidivism. In other words, it tests both whether there is an effect from $\mathrm{RJ}$ conferences and whether that effect occurs for the reasons hypothesized.

\section{Summary of the Analysis}

The analysis begins by examining the impact of the treatment variation that is central to the RISE experiment. In the drinking and driving experiment, adults were randomly assigned to either an $\mathrm{RJ}$ conference or a traditional adjudicative procedure. The analysis first examines whether the experimental treatment produced effects on subsequent adherence to the law. This tests the hypothesis underlying the RISE experiments-i.e., that RJ conferences achieve higher levels of long-term law-abidingness than do traditional adjudicatory procedures. 
Second, the analysis explores the impact of the subjective experience that people have during their participation in a conference or court processing upon their long-term orientation toward and compliance with the law. Both the procedural justice and reintegrative shaming models argue that when people experience a procedure that has appropriate psychological characteristics, irrespective of whether that procedure is a conference or a court processing, they will be influenced by that experience. This second aspect of the analysis tests the hypothesis that people who experience the process by which their case is disposed as being procedurally just or as invoking the elements of reintegrative shaming will develop a positive orientation toward the law and will follow the law in the future.

Finally, the analysis compares and integrates the results of the experimental and the psychological analyses outlined. In theory, the treatment received - conference versus court - shapes the psychological experience of the participants. Those experiencing conferences are predicted to judge them to be more procedurally just and to feel more of the emotions associated with reintegrative shaming. These psychological reactions, in turn, are predicted to lead to a long-term effect that includes a positive orientation toward and greater adherence to the law in the future.

As it turns out, in this study the psychological model worked as predicted, while the predicted differences due to experimental treatment did not emerge. The final section seeks to reconcile these disparate findings by examining the degree to which the treatments were effective in producing the key psychological effects upon which their impact depends.

\section{Methods}

\section{Sample}

The offenders in this sample were all arrested between July 1995 and December 1997. The arrests almost always occurred after the offenders were stopped completely at random under Australian legal powers. Canberra police are empowered to stop any driver at any time, without any other stated reason, in order to conduct a Breathalyzer test of blood alcohol content (BAC). If a particular level of BAC is exceeded, the offender is almost always automatically prosecuted in court (except for the cases diverted in this experiment). Most cases in this sample were detected in roadblocks set up by police in high-risk locations at high-risk times. Prosecuted cases almost always resulted in a guilty plea, conviction, suspension of driver's license, a fine, and publication of the 
offender's name in the local newspaper - all of which may be considered stigmatic shaming (J. Braithwaite 1989).

Offenders diverted to RJ conferences had their charges dropped and acquired no criminal record and no public reporting of their arrest, as long as they complied with the $\mathrm{RJ}$ requirement to attend the conference with five "supporters." These supporters were expected to be family members or friends who would help shame the act of drinking and driving while supporting the offender, although in some cases the supporters were lukewarm about the moral condemnation of the offense. Community representatives not personally connected to the offender were present at a substantial majority of the conferences (86 percent) and were generally more forceful in condemning the offender's crime, apparently more so than in any statements made in traditional court appearances. $\mathrm{RJ}$ conferences resulted in an agreement that the offender would undertake some effort to repair the harm of putting the community at risk, often including donations to charity or undertaking to do work for community organizations. Police then checked on whether the offender completed the reparation plan as promised.

The analysis of the long-term effects of case disposition upon repeat offending used three types of information. First, following their prosecution/conference, offenders were interviewed about their experience. Second, two years following their random assignment, offenders were reinterviewed about their experience. Third, police records of criminal activity for four years prior to and four years following the prosecution/conference were analyzed.

Of the 900 people assigned to treatment, 730 were interviewed shortly after their treatment in either court or conference (Time One). Of the 730 Time One treated and interviewed cases, 377 experienced a conference and 353 experienced prosecution in court. Approximately two years later, additional interviews were completed with 620 of the randomly assigned and treated cases (Time Two), 94 percent of whom $(n=580)$ had also been interviewed at Time One. ${ }^{2}$ Of the 620 Time Two interviewees, 313 people had experienced conferences and 307 had experienced prosecution in court. Police records were obtained for all 900 offenders.

The Time One treated and interviewed sample was 76 percent male. The mean age was 30.84 (median $=27.38$; range 17-74). Family incomes ranged from 0 to more than $A \$ 100,000$. In the sample, 21 percent had incomes of $A \$ 0-20,000 ; 26$ percent had

2 One interview in a case coded as no treatment (PCA\#055) and excluded from the Time Two analysis actually had been treated in conference. Nine other Time Two interviews were also completed with people who had not experienced either treatment. 
incomes from $A \$ 20,001$ to $A \$ 35,000 ; 25$ percent had incomes of $A \$ 35,001$ to $A \$ 60,000$; and 28 percent had incomes over A $\$ 60,001$. Education also varied. Eight percent had nine years of education or less; 36 percent had 10-11 years of education, ending in secondary school; and 56 percent had 12 years of education or more. Only a small group of offenders were Aborigines $(n=16$; $2.2 \%$ ), so ethnicity cannot be examined in this analysis.

\section{Measures}

Complete details about the questions asked, as well as statistical information about the scales, are included in the Appendix.

\section{Law-Related Behavior}

Behavior was assessed in two ways. First, the Australian Federal Police provided police records of criminal history four years prior to and four years following the offense. Second, when interviewed immediately after their conference/court processing, offenders were asked to indicate how frequently they drank and how often they drove while drunk during the period prior to their arrest. Third, at the second interview, which took place two years following the offense, offenders were asked to self-report both the frequency of their driving while drunk and how hard they were trying not to drive while drunk.

The intercorrelation among the measures of drinking and driving indicated that they were not highly correlated. However, self-reported post-treatment drinking and driving was correlated to four-year police records $(r=0.11, p<0.01)$. Further, those who reported that they tried not to drive after drinking during the second interview also reported less drinking and driving $(r=0.16$, $p<0.001)$. Self-reported efforts not to drive after drinking posttreatment were not linked to police records about frequency of arrest, either during the four years after the treatment $(r=-0.01$, n.s.), or in the two years following the second interview (i.e., Years $3-4$ post treatment; $r=0.06$, n.s.).

\section{The First Interview - Judgments About the Conference/Court Experience}

Offenders made three judgments about the case disposition process related to procedural justice. They evaluated the fairness of the procedures during the conference/court processing, the fairness of their treatment by the police, and the legitimacy of the legal system.

Measurement of reintegrative shaming largely followed the approach outlined by Ahmed and colleagues (2001). The model presented therein distinguishes among three aspects of reintegrative shaming: reintegration, stigmatization, and shaming. Each was 
measured. The interpersonal problems associated with recidivism were also assessed.

\section{The Second Interview}

During the second interview, offenders were asked about two general law-related attitudes. The first was the legitimacy and feelings of obligation they felt toward the law. The second was the degree to which they felt that breaking the law would create interpersonal problems between them and their family/the community.

\section{Results}

\section{Did the RJ Conferences Lower the Rate of Subsequent Reoffending?}

The first issue addressed was whether the experiment worked as intended, i.e., whether those who experienced $\mathrm{RJ}$ conferences were less likely to reoffend in the future than were those who had traditional court processing. Because the police records were categorical (i.e., the person either did or did not reoffend), logistic regression was used to examine the impact of experienced treatment on later law-related behavior (Cohen, Cohen, West and Aiken 2003).

The results of the logistic regression are shown in Table 1. The coefficients shown are unstandardized, and the number in

Table 1. The Influence of Experienced Treatment on Police Recorded Recidivism

\begin{tabular}{lc}
\hline & Years 1-2 \\
\hline Treatment & -0.43 \\
Past frequency-police records & $(0.30)$ \\
Past frequency-driving drunk & -0.13 \\
Past frequency-drinking & $(0.43)$ \\
Age & $0.14^{*}$ \\
Gender & $(0.07)$ \\
Years of education & -0.05 \\
Income & $(0.12)$ \\
Chi-square & $0.10^{* *}$ \\
Cox and Snell R-sq. & $(0.02)$ \\
$N$ & 0.79 \\
Percent reoffending & $(0.46)$ \\
\end{tabular}

Note: Because the dependent variable was dichotomous (did or did not reoffend), logistic regression was used. The numbers shown are unstandardized coefficients, and the numbers in parentheses are the standard error.

$* p<0.05, * p<0.01, * *<<0.001$. 
parentheses is the standard error. There were two dependent variables: behavior during Years 1-2 (10\% reoffended) and behavior during Years 3-4 (8\% reoffended). The analysis examined the influence of the treatment experienced (conference, court) on later behavior. The results indicated that treatment did not have a significant influence upon reoffending behavior for either of the two indices of police-recorded reoffending. In the case of Years 1-2, the equation explained a significant amount of variance in recidivism $(7 \%$, Chi-square $=35.96$ ( 8 d.f.), $p<0.001)$, so the equation is shown in Table 1 . The equation did not explain a significant amount of variance in recidivism during Years 3-4 (2\%, Chisquare $=11.44$ ( 8 d.f.), n.s., so that equation is not shown. In neither case, however, did treatment significantly shape recidivism. In Years 1-2, recidivism was shaped by the influence of prior selfreported drunk driving and by age.

A second set of indices of post-treatment behavior were based upon self-report at the second interview, which occurred two years following the treatment. At that time those in the study indicated both how often they drove while drunk post-treatment and how hard they were trying to avoid driving while drunk, again during the post-treatment period. Because these dependent variables were not categorical, regression analysis was used.

The results of the analysis are shown in Table 2. In the case of self-reported frequency of driving while drunk, there was no significant treatment effect (standardized regression coefficient $=$ 0.00 , n.s.). However, an effect was observed for treatment on self-reports of efforts to curb driving while drunk, with those

Table 2. Self-Reported Behavior and Attitudes During the Second Interview (Two Years Following the Treatment)

\begin{tabular}{lcccc}
\hline & $\begin{array}{c}\text { Self-Report of } \\
\text { Drinking and } \\
\text { Driving }\end{array}$ & $\begin{array}{c}\text { Self-Report } \\
\text { of Efforts Not to } \\
\text { Drink and Drive }\end{array}$ & $\begin{array}{c}\text { Legitimacy } \\
\text { of the Law }\end{array}$ & $\begin{array}{c}\text { Reoffending } \\
\text { Would be } \\
\text { a Problem }\end{array}$ \\
\hline $\begin{array}{l}\text { Treatment } \\
\text { Past frequency }\end{array}$ & 0.00 & $0.10^{*}$ & $0.14^{* * *}$ & $0.11^{* *}$ \\
$\begin{array}{l}\text { police records } \\
\text { Past frequency- }\end{array}$ & 0.00 & -0.07 & -0.01 & 0.08 \\
$\begin{array}{l}\text { driving drunk } \\
\text { Past frequency- }\end{array}$ & $0.24^{* * *}$ & 0.04 & -0.08 & -0.08 \\
$\begin{array}{l}\text { drinking } \\
\text { Age }\end{array}$ & $0.12^{* * *}$ & 0.05 & -0.03 & $-0.11^{*}$ \\
$\begin{array}{l}\text { Gender } \\
\text { Years of education }\end{array}$ & 0.01 & $0.26^{* * *}$ & 0.05 & -.08 \\
$\begin{array}{l}\text { Income } \\
F\end{array}$ & 0.07 & $0.10^{*}$ & $-0.16^{* * *}$ & $-0.15^{* * *}$ \\
d.f. & 0.01 & 0.01 & -0.03 & -0.01 \\
Adjusted R-sq. & 0.01 & 0.04 & 0.03 & -0.02 \\
\hline
\end{tabular}

Because the dependent variables were scales, regression analysis was utilized. The numbers shown are standardized regression coefficients.

${ }^{*} p<0.05,{ }^{* *} p<0.01,{ }^{* * *} p<0.001$. 
who went to conferences indicating that they made more effort not to drive while drunk (standardized regression coefficient $=0.10$, $p<0.05$ ).

Overall, these results suggest that the RJ procedure was not more successful in motivating adults to later follow the law. Irrespective of whether the dependent variable was police-reported or self-reported recidivism, direct effects of the treatment were not generally found. The only effect observed was on self-reported efforts not to drive while drunk.

On the other hand, when the focus of concern was upon the key psychological characteristics - viewing the law as legitimate and believing that rule-breaking would be a problem-a treatment effect emerged. Two years after they experienced the treatment, those participants who were involved in a conference, as opposed to having traditional court processing, indicated that the law was more legitimate (standardized regression coefficient $=0.14$, $p<0.001$ ) and said that repeat offending would create greater interpersonal problems in their lives (standardized regression coefficient $=0.11, p<0.01$ ). Hence, while the treatment did not directly influence recidivism, it did affect people's orientations toward the law, with those who attended conferences viewing the law as more legitimate and believing that breaking the law would create more problems in their lives.

The failure to find a direct treatment effect could occur for several reasons. One is that the treatment did not work, another is that it was poorly designed and/or implemented. In the case of the RISE experiment, a number of issues of design and implementation might account for the failure to find treatment effects. On a conceptual level, driving-while-drunk arrests usually occurred without any clear "victim," so conferences could not include a victim. Hence, the processes such as remorse and guilt were difficult to create, and true reintegrative emotions were hard to engage (Mugford 2003). And contrary emotions such as resentment and anger might have been stirred by efforts to use conference procedures with crimes in which there was not a clear victim and a directly identifiable harm.

When the program was being implemented, there were large differences between the police officers in how well they led conferences. Some officers were well qualified and knowledgeable about the theory behind the procedures, but others became involved in the project by assignment or because they believed leading a small number of conferences would be a valuable career credential. And without any specific victim, the conferences varied widely in the nature of the community representation that was involved in any particular conference. Hence, the quality of the conferences varied considerably. 


\section{Did the Psychological Models Work?}

The failure of the experimental treatment did not provide support for the arguments underlying procedural justice and reintegrative shaming models. It is important to ask, therefore, whether the findings of this study provided other types of evidence in support of these models. The psychological models hypothesize that experiencing procedural justice and reintegrative shaming would encourage a favorable orientation toward the law and lead to higher levels of adherence.

How should the psychological constructs be assessed? The intercorrelation among psychological judgments indicates that, consistent with prior studies (Tyler 2006a), the three indexes of procedural justice - the procedural justice of the procedure, the procedural justice of the police, and the legitimacy of the lawwere correlated (mean $r=0.40$ ). In the case of reintegrative shaming, however, integration, shaming, and whether rule-breaking would be an interpersonal problem were linked (mean $r=0.41$ ), but stigmatization was unrelated to these indices (mean $r=-0.04$ ). As a result, reintegrative shaming was conceptualized as including integration, shaming, and whether rule-breaking would be an interpersonal problem. The mean correlation among these three indices was $r=0.41$. Stigmatization was not included.

For each of the psychological constructs, an overall index was created by summing across standardized indices of the three elements of each construct. In the case of procedural justice, the procedural justice of the conference/court processing, the procedural justice of the police, and the legitimacy of the law were combined. With reintegrative shaming, integration, shaming, and whether rule-breaking would be an interpersonal problem were combined.

The psychological argument can be directly tested by examining the influence of (1) the attitudes--i.e., whether the law is legitimate and whether reoffending would create interpersonal problems-expressed during the Time Two interview, and (2) judgments about the procedural justice and reintegrative shaming associated with the initial conference/court processing, assessed during the Time One interview. Because these analyses have behavior as their dependent variable, logistic regression was utilized. And because legitimacy and the interpersonal problems of recidivism were measured two years after the initial procedure, only behavior during Years 3 and 4 was considered for these variables.

The analysis first considered the influence of legitimacy and the interpersonal problems associated with recidivism (measured during the second interview) on recidivism behavior after the second interview (Years 3-4). This is Model 1. The results of the analysis are shown in Table 3. The coefficients shown are not standardized, 
Table 3. The Influence of Legitimacy and Problem Evaluation on PoliceRecorded Recidivism

\begin{tabular}{|c|c|c|c|}
\hline \multirow[b]{3}{*}{ DV = police-recorded recidivism } & \multirow{3}{*}{$\begin{array}{c}\begin{array}{c}\text { Influence of } \\
\text { Legitimacy and } \\
\text { Interpersonal } \\
\text { Problems }\end{array} \\
\text { Model } 1 \\
\text { Years 3-4 }\end{array}$} & \multicolumn{2}{|c|}{$\begin{array}{l}\text { Influence of } \\
\text { Procedural Justice } \\
\text { and Reintegrative } \\
\text { Shaming }\end{array}$} \\
\hline & & Model 2 & Model 3 \\
\hline & & \multicolumn{2}{|c|}{ Years $1-2$} \\
\hline Legitimacy (2nd interview) & $\begin{array}{c}-0.65 * * \\
(0.21)\end{array}$ & - & - \\
\hline Interpersonal problem (2nd interview) & $\begin{array}{c}-0.13 \\
(0.31)\end{array}$ & - & - \\
\hline Procedural justice (lst interview) & - & $\begin{array}{c}-0.55 \\
0.36)\end{array}$ & $\begin{array}{r}-0.66 \\
(0.36)\end{array}$ \\
\hline Reintegrative shaming (1 st interview) & - & $\begin{array}{c}0.29 \\
(0.29)\end{array}$ & $\begin{array}{c}0.42 \\
(0.37)\end{array}$ \\
\hline Interaction & - & - & $\begin{array}{r}-0.19 \\
(0.18)\end{array}$ \\
\hline Past frequency - police records & $\begin{array}{r}-0.40 \\
(0.58)\end{array}$ & $\begin{array}{r}-0.07 \\
(0.43)\end{array}$ & $\begin{array}{c}-0.06 \\
(0.12)\end{array}$ \\
\hline Past frequency-driving drunk & $\begin{array}{r}-0.02 \\
(0.08)\end{array}$ & $\begin{array}{c}0.14^{*} \\
(0.07)\end{array}$ & $\begin{array}{r}0.14^{*} \\
(0.06)\end{array}$ \\
\hline Past frequency-drinking & $\begin{array}{c}0.22 \\
(0.16)\end{array}$ & $\begin{array}{c}-0.05 \\
(0.12)\end{array}$ & $\begin{array}{c}-0.09 \\
(0.12)\end{array}$ \\
\hline Age & $\begin{array}{r}-0.04^{*} \\
(0.02)\end{array}$ & $\begin{array}{c}-0.09^{*} \\
(0.02)\end{array}$ & $\begin{array}{c}-0.09 \\
(0.02)\end{array}$ \\
\hline Gender & $\begin{array}{c}0.27 \\
(0.52)\end{array}$ & $\begin{array}{c}0.89 \\
(0.47)\end{array}$ & $\begin{array}{c}0.96^{*} \\
(0.47)\end{array}$ \\
\hline Years of education & $\begin{array}{r}-0.04 \\
(0.17)\end{array}$ & $\begin{array}{r}-0.23 \\
(0.14)\end{array}$ & $\begin{array}{c}-0.22 \\
(0.14)\end{array}$ \\
\hline Income & $\begin{array}{c}0.00 \\
(0.04)\end{array}$ & $\begin{array}{c}0.01 \\
(0.03)\end{array}$ & $\begin{array}{c}0.0 \mathrm{I} \\
(0.03)\end{array}$ \\
\hline Chi-square & $\begin{array}{c}19.03^{*} \\
(9 \text { d.f. })\end{array}$ & $\begin{array}{l}37.06^{*} \\
(9 \text { d.f. })\end{array}$ & $\begin{array}{l}39.82^{*} \\
\text { (10 d.f.) }\end{array}$ \\
\hline $\begin{array}{l}\text { Cox and Snell R-sq. } \\
N \\
\text { Percent reoffending }\end{array}$ & $\begin{array}{l}.05 \\
415 \\
8 \%\end{array}$ & $\begin{array}{r}.07 \\
540 \\
10 \%\end{array}$ & $\begin{array}{r}.07 \\
540 \\
10 \%\end{array}$ \\
\hline
\end{tabular}

Because the dependent variable was dichotomous (did or did not reoffend), logistic regression was used. The numbers shown are unstandardized regression coefficients. The standard errors are in parentheses.

$$
{ }^{*} p<0.05, * p<0.01, * 0<0.001 \text {. }
$$

and standard errors are shown in parentheses. The analysis indicates that the findings for legitimacy are consistent with the hypothesis. Those who viewed the law as more legitimate were found to be less likely to show recidivism, as reflected in police records (Model 1: unstandardized coefficient $=-0.65, p<0.01$ ).

The analysis also examined the influence of procedural justice and reintegrative shaming (measured at the first interview) upon later recidivism. That analysis is divided into an examination of influences upon recidivism during Years 1-2 and recidivism during Years 3-4. A significant amount of variance in recidivism during Years 1-2 was explained by the basic equation (7\%, Chisquare $=37.06$ (9 d.f.), $p<0.001$ ), so equations using that dependent variable are shown in Table 3 . The basic equation with recidivism during Years $3-4$ did not explain a significant amount 
of variance in recidivism ( $2 \%$, Chi-square $=10.61$ (9 d.f.), n.s.), so no equations using that dependent variable are shown in Table 3.

The analysis of recidivism in Years 1-2 considered two models. The basic model is Model 2. A model with the interaction term reflecting the joint influence of procedural justice and reintegrative shaming is Model 3. The results of the analysis using both of these equations are shown in Table 3 . The analysis in Table 3 indicated that there was no relationship between procedural justice, reintegrative shaming, and police-recorded recidivism. The Model 2 analysis shown in Table 3 presented the effects of procedural justice and reintegrative shaming upon recidivism as two main effects. No effects were found. It is also possible that these two processes interact, i.e., that people are especially likely not to reoffend when they experience both procedural justice and reintegrative shaming, and vice versa. To test this possibility, the analysis shown in Table 3 was repeated with an interaction term included (Model 3). That interaction was also not significant.

These findings suggest that the key issue shaping recidivism was the degree to which people viewed the law as legitimate. If people viewed the law as legitimate two years after their treatment, then they were significantly less likely to be breaking the law. And this effect occurred with police-recorded law violations, suggesting that it was not a reflection of self-report biases.

The analysis of the relationship between legitimacy and policerecorded offending also provided an opportunity to address the question of whether the influence of legitimacy was not just statistically significant, but also substantial. One way to address this question was to consider the estimates of percent of variance explained by logistical regression (see Cohen et al. 2003). That procedure estimates that approximately 5 percent of the variance in recidivism was explained by the variables in the equation.

A second approach was to divide offenders into high- and lowlegitimacy groups and examine the rate of recidivism within each group. To do so, those interviewed at Time Two were divided into four groups based upon their judgments about the legitimacy of the law: very high legitimacy $(n=90)$, high legitimacy $(n=93)$, low legitimacy $(n=175)$, and very low legitimacy $(n=122)$. The rate of recidivism was then examined within each group. The rates were 3.3 percent for the very high group, 5.4 percent for the high group, 9.1 percent for the low group, and 15.6 percent for the very low group. In other words, those who viewed the system as highly legitimate were about 12 percent less likely to be rearrested during Years 3-4 than those who accorded very low legitimacy to the system.

Regression analysis was also used to see whether legitimacy was linked to self-reported recidivism, as expressed during the second 
Table 4. The Influence of Legitimacy Upon Self-Reported Behavior

\begin{tabular}{lcc}
\hline & $\begin{array}{c}\text { Self-Reported } \\
\text { Rate of Driving } \\
\text { While Drunk } \\
\text { Second Interview }\end{array}$ & $\begin{array}{c}\text { Self-Reported } \\
\text { Efforts to Not } \\
\text { Drive While } \\
\text { Drunk-Second } \\
\text { Interview }\end{array}$ \\
\hline Legitimacy (second interview) & $0.25^{* *}$ & $0.20^{* *}$ \\
Past frequency-police records & 0.00 & 0.07 \\
Past frequency-driving drunk & $0.22^{* * *}$ & 0.03 \\
Past frequency-drinking & $0.11 *$ & 0.04 \\
Age & 0.02 & 0.27 \\
Gender & 0.03 & 0.07 \\
Years of education & 0.00 & 0.00 \\
Income & 0.02 & 0.04 \\
F & $12.60^{* * *}$ & $10.92 * *$ \\
d.f. & 8,534 & 8,536 \\
Adjusted R-sq. & $.15 * *$ & $.13^{* * *}$ \\
\hline
\end{tabular}

Because the dependent variable was a scale, regression analysis was utilized. The numbers shown are standardized regression coefficients.

$* p<0.01, * 0<0.001$.

interview. The results are shown in Table 4. Those who indicated that the law was more legitimate also self-reported lower frequencies of driving while drunk (standardized regression coefficient $=0.25, p<0.001)$ and said that they were making greater efforts not to drink and drive (standardized regression coeffcient $=0.20, p<0.001$ ). These results indicate that legitimacy explained about 13-15 percent of the variance of self-reported behavior. This conclusion is similar to that suggested by the prior analysis, in which the high- and low-legitimacy groups differed 12 percent in their police-recorded rate of recidivism.

\section{The Antecedents of Legitimacy}

While procedural justice and reintegration did not directly influence reoffending behavior, they may nonetheless be important as antecedents of legitimacy. It was legitimacy in particular that emerged as the key to declines in reoffending in the analysis shown in Table 3. Regression analysis was used to explore the influence of procedural justice and reintegrative shaming, psychological motivations measured immediately following the conference or court processing, upon legitimacy, as measured two years later. The results of that analysis are shown in Table 5 .

The regression analysis shown in Table 5 provided support for both of the psychological models outlined. Both procedural justice (standardized regression coefficient $=0.24, p<0.001$ ) and reintegrative shaming (standardized regression coefficient $=0.21$, $p<0.001$ ) shaped later legitimacy. Hence, while neither procedural justice nor reintegrative shaming influenced reoffending behavior directly, they did influence reoffending by shaping later views 
Table 5. Impact of Evaluations of the Case Disposition Process on Later Legitimacy

\begin{tabular}{lcc}
\hline & \multicolumn{2}{c}{ Legitimacy of the Law (Second } \\
Interview)
\end{tabular}

Because the dependent variable was a scale, regression analysis was utilized. The numbers shown are standardized regression coefficients.

$* p<0.05, * *<<0.01, * * 0.001$.

about the legitimacy of the law. An interaction analysis, shown in the second column of Table 5 , indicates that the two processes separately shaped legitimacy.

\section{Reconciling the Findings}

The psychological analysis supported the psychological models outlined. Those who experienced greater procedural justice and higher levels of reintegrative shaming during their conference or court processing were found two years later to view the law as more legitimate. That later legitimacy, in turn, led to reduced levels of offending. However, the results suggest that the form of treatment experienced did not directly influence the rate of later reoffending.

One possible explanation for these findings is that the two forms of treatment-conference and court processing-did not differ in their psychological characteristics. This possibility was examined by comparing the mean level of procedural justice and reintegrative shaming for conferences and court processing. The results are shown in Table 6 . They indicate that, as predicted, conferences were judged to be more procedurally just and to motivate higher levels of reintegrative shaming. This was true for all three measures of procedural justice, all three measures of reintegrative shaming, and for judgments about both the legitimacy of the law and the interpersonal problems associated with recidivism, as measured both after the conference/court processing and two years later. All measures showed conferences to have significantly more psychological impact.

These psychological measurements suggest that conferences worked as desired and that the best explanation for the failure of 
Table 6. Mean Levels of Procedural Justice and Shaming by Experienced Treatment

\begin{tabular}{|c|c|c|c|c|c|}
\hline & \multirow{2}{*}{$\begin{array}{l}\text { Experienced } \\
\text { Conference }\end{array}$} & \multirow{2}{*}{$\begin{array}{l}\text { Experienced } \\
\text { Prosecution }\end{array}$} & \multirow{2}{*}{$\begin{array}{c}\text { Mean } \\
\text { Difference }\end{array}$} & \multicolumn{2}{|c|}{$t$-test } \\
\hline & & & & d.f. & $t$ \\
\hline Procedural justice of the procedure & $3.79(0.51)$ & $3.31(0.68)$ & 0.48 & 726 & $10.84 *$ \\
\hline $\begin{array}{l}\text { Procedural justice of police } \\
\text { treatment }\end{array}$ & $4.06(0.49)$ & $3.45(0.64)$ & 0.61 & 727 & $14.54 *$ \\
\hline Legitimacy of the law at Time One & $4.40(0.47)$ & $4.22(0.50)$ & 0.18 & 725 & $5.94 *$ \\
\hline Reintegration & $2.92(0.66)$ & $1.92(0.79)$ & 1.00 & 725 & $18.63 *$ \\
\hline Shaming & $3.25(0.86)$ & $2.90(0.87)$ & 0.35 & 726 & $5.45^{-\infty *}$ \\
\hline $\begin{array}{l}\text { Interpersonal problems of } \\
\text { recidivism - Time One }\end{array}$ & $3.40(0.53)$ & $3.27(0.61)$ & 0.13 & 578 & $2.80^{-m}$ \\
\hline Legitimacy of the law at Time Two & $4.21(0.69)$ & $3.98(0.85)$ & 0.23 & 573 & $3.51-$ \\
\hline $\begin{array}{l}\text { Interpersonal problems of } \\
\text { recidivism-Time Two }\end{array}$ & $3.40(0.53)$ & $3.27(0.61)$ & 0.13 & 576 & $2.69^{* *}$ \\
\hline
\end{tabular}

recidivism-Time Two

${ }^{*} p<0.05,{ }^{* *} p<0.01, * * 0<0.001$.

the experimental treatment to have an impact was the weakness of the treatment. The treatment had the desired influence but did not produce a strong-enough effect to impact behavior. The theory underlying the RISE experiments is sound, and the predicted psychological dynamics occurred. However, for the many reasons outlined earlier, the treatment was too weak to produce strong direct influences on reoffending behavior. Hence, a more effectively designed and delivered treatment would have produced the anticipated treatment effect.

\section{Discussion}

There are many attractive features of RJ conferences. For example, they are found to be more satisfying for victims of crime (Strang 2002), and they have many positive psychological effects on offenders (Barnes 1999; Poulson 2003). Hence, even if RJ conferences did not lead to a lower rate of reoffending over time, they might have social value and be publicly popular (Roberts \& Stalans 2004 ), provided they did not actually increase reoffending. Nonetheless, the suggestion that $\mathrm{RJ}$ conferences lower the rate of reoffending over time is one aspect of their widespread adoption, and this empirical claim needs to be tested.

The results of this study do not support the argument that diverting adult drinking-and-driving cases from traditional adjudication to $\mathrm{RJ}$ conferences will lower the rate of subsequent reoffending. There is no significant difference between the policerecorded reoffending behavior of people assigned to the two groups, and only limited evidence of treatment differences in selfreported behavior. Hence, this study does not provide any additional evidence of a direct link between conferences and lowered rates of reoffending. 
However, the results support the argument that the psychological dynamics identified by procedural justice and reintegrative shaming models, when either one is activated, lead to reductions in reoffending. Hence, the results of the study lend support to the hypothesis that the use of $\mathrm{RJ}$ conferences could potentially lead to reductions in recidivism, but only if the necessary psychological mechanisms are engaged by the offender's experience. The crimereducing influence, in other words, is not an automatic result of being diverted from prosecution, but it only occurs if the conferences activate the psychological mechanisms of procedural justice and reintegrative shaming.

If the appropriate psychological forces were activated then, years after they participated in a $\mathrm{RJ}$ conference or court processing, adults charged with drinking and driving were more supportive of the law and less likely to reoffend, relative to those offenders sent to court. Again, however, this was only true if the conference was experienced as procedurally just and if it led the offenders to feel reintegrative shame. And these effects were modest in their magnitude, with legitimacy accounting for somewhere between 5 and 15 percent of the variance in police-recorded reoffending.

And of course, while not part of the theoretical framework, it is important to note that demographics mattered. In particular, women were more likely to view the law as legitimate and to think that reoffending would create interpersonal problems. In addition, as people grew older they reported trying harder not to reoffend and were generally found to be less likely to be rearrested for reoffending.

Two aspects of the findings show promise. First, reductions occurred if psychological mechanisms were engaged even when reoffending was indexed by police records. Since the potential problems of self-reported offending are well known, it is important that the reduction in reoffending is documented using police-reported crimes. Because of the random nature of police stops with this particular offense, this is an ideal setting in which to use police records to index offending. However, even in this case, the probability of being arrested for an offense is low. It is therefore encouraging that the results for police-recorded and self-reported behavior were similar.

Second, the reduction in behavior persisted over time. In this case, respondents were interviewed two years after their initial experience, and there were still clear increases in support for the law and reductions in rule-breaking linked to their experiences. In particular, reductions in police-reported rule-breaking were found for Years 3 and 4.

This study suggests that the strength of the impact of conferences depends upon their ability to effectively lead offenders to feel 
both fairly treated and that their ties to others have been restored through reintegrative shaming. The real power of conferences is engaged when they create the desired and desirable psychological conditions leading to rule-following, i.e., procedural justice and reintegrative shaming.

It is also important to note that, although separate results are not presented for those in prosecution and in $\mathrm{RJ}$ conferences, the study found similar dynamics within conferences and prosecution. That is, while those who were involved in conferences experienced higher levels of procedural justice and more reintegrative shaming, within both conferences and court those who experienced these feelings were less likely to reoffend. This suggests that it would also be possible to lower the rate of recidivism by redesigning traditional court-based prosecution experiences.

Since conferences were more likely to create the psychological dynamics needed to lower reoffending than were court appearances, redesigning court processes would be an inferior strategy in comparison to diversion into appropriately designed conferences. However, if diversionary programs did not exist and could not be created, those managing courts could address the issue of recidivism by trying to understand how people could experience procedural justice and reintegrative shaming within a court context. That understanding could then be used to redesign court procedures.

The findings of this study suggest strongly that under the right conditions $\mathrm{RJ}$ conferences can have positive influences on future attitudes and behavior. The challenge for future research is to identify which $\mathrm{RJ}$ processes provide the greatest opportunity to use $\mathrm{RJ}$ to reduce recidivism. The findings point to a clear need to better understand how the features of RJ conferences/court cases map onto their psychological impact, and how similar RJ procedures may affect different kinds of people depending upon their predispositions. While it is not possible to rule out all possible dispositional explanations for the effects observed, without relying upon randomized assignment to treatments, controls were made upon demographic variables to eliminate some potential prior influences.

The best way to increase the impact of $\mathrm{RJ}$ conferences on subsequent behavior is therefore to better understand how such conferences lead offenders to feel fairly treated by the system and ashamed of their behavior. Participation in an RJ conference is not, in and of itself, an effective psychological experience. The conference has to create the desired psychological characteristics to produce a long-term impact. A further analysis of observer ratings indicated that high levels of free choice, high levels of participation, and low levels of moral condemnation were all features of 
procedures that encouraged participants to feel that the conferences were just procedures and to experience reintegrative shaming.

The two paths of influence found in this study correspond to the two arguments underlying the RJ literature about why conferences should influence people. First, successful conferences incorporated the features associated with procedural justice, features such as opportunities to participate and to have others take account of one's views. They also allowed other people the opportunity to demonstrate that their motivations were trustworthy and that they understood the perspective of the offender, the victim, and others at the conference. Procedural fairness is widely associated with legitimacy judgments and, through legitimacy, with rule-following (Tyler 2006a, 2006b; Tyler \& Huo 2002), and that connection was also found in this analysis.

The other path is associated with reintegrative shaming. In this path, some people restored their ties to others after experiencing shame over their behavior, and it was concern about those ties that motivated subsequent rule-following. In this study, people who said that the treatment restored their connections to others indicated both that the law was more legitimate and that it would be more of a personal problem to them to break rules, an action that would again undermine those interpersonal ties. These findings point, in particular, to reintegrative shaming as a mediating variable shaping the influence of conferences upon later behavior.

These findings suggest that there were two reasons that people are more likely to follow rules after the transgression of drinking and driving. First, their commitment to and sense of obligation toward law and legal authorities has been strengthened. Second, their emotional connections to others-family, friends, members of the community, and possibly authorities--are also strengthened and they therefore think that future transgressions would be more problematic for them and their family. Both reasons were linked in this study to the motivation to obey the law.

As already noted, this extension is important because the cases studied here reflect the type of everyday law-related behavior among adults that is central to the viability of law and the legal system. Driving while under the influence of alcohol is a behavior that is widespread within the adult population of Australia, as well as in other Western countries. It reflects a type of behavior that is difficult to control without the massive deployment of law enforcement resources, and a behavior that could most desirably be managed via self-regulation (Tyler 2003).

What is the relationship between the psychological processes associated with procedural justice and with reintegrative shaming? Common ideas such as having a chance to express one's views and having evidence that one's concerns are attended to occur within 
both literatures. Here the two processes were found to be connected, with those who indicated that a procedure was just also indicating that it led to reintegrative shaming $(r=0.49, p<0.001)$. This suggests that participants experienced the two psychological processes under similar circumstances.

However, interaction effects were not found when procedural justice and reintegrative shaming were considered together. People were not especially likely to view the law as legitimate, nor were they especially likely not to reoffend if they indicated that they both experienced procedural justice and felt reintegrative shaming. Instead, the two psychological judgments were additive, with each contributing some influence to judging the law to be legitimate and to subsequent law-abiding behavior. This suggests that the two psychological processes were distinct, but had parallel influences.

\section{Legitimacy and Compliance}

Legitimacy has long been recognized as an important property for law and legal authorities to possess (Tyler 2006a, 2006b). It is argued that when people view the law as legitimate, they take the responsibility and obligation to obey the law unto themselves and are more likely to comply, especially in situations in which the likelihood of detection is low.

The dynamics of legitimacy are supported by the findings of this study. Legitimacy is found to shape compliance with the law, with those who view the law as legitimate more likely to obey it. This relationship is found with both police-recorded reoffending and self-reported rule-breaking. In both cases, as predicted by sociolegal models, legitimacy motivates compliance.

Further, as predicted by psychological models of legitimacy (Tyler 2006a, 2006b), procedural justice shapes legitimacy. In this case, the procedural justice of the conference/court processing is found to shape legitimacy two years after that experience. Hence, these findings support the suggestion that procedural justice contributes to long-term adherence to the law by enhancing supportive attitudes toward the legal system. In addition, the findings suggest that the experience of reintegrative shaming also shapes legitimacy. This finding is an important addition to the existing literature on legitimacy, linking legitimacy to the RJ movement and to the conferences developed and implemented within the context of that movement. While it has been widely suggested that the emotions aroused within such conferences may shape people's subsequent interpersonal relationships, leading to the motivation not to reoffend due to the desire not to disappoint others, the findings of this study suggest that the use of $\mathrm{RJ}$ conferences also 
enhances compliance by building the legitimacy of the law. Of course, this is not completely surprising. As noted, the psychological dynamics of reintegrative shaming and of procedural justice are similar. Nonetheless, this study finds that procedural justice and reintegrative shaming have distinct influences upon legitimacy, suggesting that each makes a distinct contribution to people's views about the legitimacy of the law.

While this study supports the basic argument that legitimacy shapes recidivism, it is also important to consider factors that might shape the strength of this relationship. This is particularly true in this case, since the impact of legitimacy, while clearly found, was not particularly strong. Several explanations are possible. First, the legitimacy of regulatory agencies may be weak (Hayden 1989). In the case of Australia, there is some evidence that the public has a skeptical view of regulatory authorities, a recent focus of which is public discontent with the agency in charge of tax collection (V. Braithwaite 2003; Murphy 2004). In addition, as we outlined earlier in the article, the legitimacy of the laws and procedures associated with arrests for driving while drunk may lack legitimacy. In the absence of a clear victim and harm, some offenders were skeptical about their arrest and case adjudication, particularly those who participated in $\mathrm{RJ}$ conferences. It is well established that if a particular law is not supported by morality, participants are less likely to view the legal process involving it as legitimate (Robinson \& Darley 1995, 1997; Tyler 2006a, 2006b). Hence, it is not particularly surprising that the effects of the legitimacy of the law were weak in this study.

\section{Limits of the Findings}

This study was not based on the direct impact of the randomly assigned experimental treatment (court/conference) upon later behavior because no direct experimental effect was found. Rather, it used a nonexperimental approach linked to the psychological processes activated by legal procedures. One reason for the value of this nonexperimental approach to assessing influence in this particular case was that observations of the RJ conferences undertaken during the RISE experiment suggested wide variations in the degree to which the conferences had the characteristics that, on theoretical grounds, were predicted to lead to the creation of the psychological impact that would be expected in turn to lead to declines in future crime-related behavior.

The design problems of RISE conferences in this setting have already been noted. Drinking and driving is most often a crime without a victim, so the traditional structure of an RJ conference 
does not fit this situation. In addition, among the implementation problems that occurred were wide variations in the training and commitment of the officers involved in the conferences, variations in the characteristics of the offenders, and variations in their attitudes, and those of their supporters, toward the offense. In keeping with the victimless nature of the offense, offenders often lacked the requisite feelings of remorse and guilt anticipated to be found among offenders. And their supporters, rather than condemning the offenders' actions, sometimes shared their view that remorse and guilt were unnecessary.

The approach used here was designed to ask whether, when conferences did create the desired psychological dynamics, they produced observable effects on behavior. And the results suggest strongly that when they do create these psychological characteristics they lead to long-term reductions in the rate of reoffending among adults arrested for a common crime-drinking and driving.

Because this study focuses upon an empirical test of the psychological mechanisms of reintegrative shaming and procedural justice, it is necessary to have a method for operationalizing these mechanisms. This study draws upon the work of John Braithwaite for guidance concerning how to measure reintegrative shaming and Tyler for guidance about how to measure procedural justice. As the literature on these ideas has developed, the theoretical richness of each has increased. As a consequence, there are now more aspects of these ideas that can be drawn upon to test these theories. This study tests the utility of one particular model of reintegrative shaming and procedural justice, and other models can also be operationalized and tested.

Just as the type of treatment has no direct effect upon recidivism, immediate judgments about treatment, i.e., whether it was just and whether it led to reintegrative shaming, have no direct effect on recidivism. Their impact occurs through their influence upon support for the law. In the analysis of the Year 3 and 4 recidivism behavior, the impact of the psychological processes studied occurs through their influence upon support for the law, i.e., upon legitimacy.

\section{Conclusion}

As is often the case with criminal justice innovation, the popularity and use of RJ conferences has moved rapidly ahead of the existence of clear evidence that such conferences produce their desired outcomes. This article examines one of those desired outcomes - the lowering of recidivism. Despite the lack of an observed treatment effect, the results lead us to be optimistic that properly 
designed and implemented procedures can lower the rate of reoffending among adult offenders. Hence, the findings reported here suggest that there are alternatives to traditional adjudication that can more effectively address the issue of recidivism.

The findings make clear that the influence of both procedural justice and reintegrative shaming on recidivism in Years 3 and 4 occurred through their influence upon Time Two attitudes. Those individuals who felt at Time Two that the law was legitimate were less likely to later break the law. Hence, the issue is how those attitudes toward law were formed. In this study, procedural justice and reintegrative shaming at the time of the treatment were found to shape attitudes two years later.

Such a demonstration of long-term influence upon behavior comes at an important time. Because of past sentencing policies, large numbers of offenders have been imprisoned. These offenders are emerging from prison in record numbers, raising the issue of how society can cope with their reentry into the general population (Travis 2004). This problem, combined with the high costs of maintaining large prison populations, is directing new attention to the question of whether there are effective alternatives to imprisonment. One clear alternative is designing procedures for dealing with initial lawbreaking that lead to lower rates of recidivism. Procedures that succeed in maximizing perceptions by offenders of procedural justice and the experience of reintegrative shaming are likely to lead to lower rates of recidivism and thus potentially lower rates of imprisonment.

\section{Appendix}

\section{Police Records}

One index of offending is official criminal history data, provided by the Australian Federal Police. Police records indicate the prevalence of arrests for drinking and driving during the four years prior to and the four years following the offender's random assignment. According to police records, 90 percent of offenders had no arrests in the four years prior to their offense, and the rest had been arrested at least once. In the four years following their initial offense, 83 percent of the offenders had no further arrests, while 17 percent had one or more further arrests for drinking and driving.

Separate analyses were conducted of police-reported drinking and driving during Years 1 and 2 and during Years 3 and 4, since this latter period occurred after the follow-up interview. Records indicated that during Years 1 and 2, 10 percent of offenders reoffended at least once. During Years 3 and 4, 8 percent of respondents reoffended. 


\section{First Interview-Self-Reported Prior Behavior}

During the first interview, which occurred shortly after their experience with a conference or in court, offenders were asked to self-report how many times they had driven over the legal alcohol limit in the 12 months prior to the conclusion of their conference or court case. This scale was skewed, so a transformation was used to create a more normal distribution. The transformation collapsed all estimates over 7 , creating a variable ranging from 0 to 7 . The median number of times reported was 5 (mean $=4.40$, standard deviation $=2.53) .^{3}$

\section{First Interview - Self-Reported Prior Frequency of Drinking}

During the first interview, offenders were asked how many times they drank alcohol. The scale ranged from never (1) to every day (8). The median response was 6 (2-3 times a week), while the mean was 5.91 (standard deviation $=1.37)$.

\section{Second Interview - Self-Reported Efforts to Avoid Drinking and Driving}

When interviewed approximately two years after the first interview, respondents were asked about the degree to which they made efforts to lower the rate of drinking and driving for themselves and for others. Four items were used: "How often do you use public transportation, such as taxis or buses, to get home after drinking?"; "If you have been drinking, how often do you sleep at a friend's house or some other place rather than driving?"; "How often do you warn others about driving when they have had too much to drink?; "If others have had too much to drink, how often do you offer to drive them home, or find another driver, or get a taxi for them?" These items were combined into a single index $($ mean $=3.40$, standard deviation $=0.64)$.

\section{Second Interview - Self-Reported Frequency of Drinking and Driving}

During the second interview, respondents were asked to estimate how often they had driven when their alcohol level was over the legal limit during the 12 months prior to their interview. There were 620 valid responses, and 58 percent indicated that they never drove while over the legal limit. Of the remaining 42 percent,

3 The analysis of the impact on police-recorded behavior was conducted controlling for self-reported frequency of driving while drunk, with that variable transformed and untransformed. The results using a transformed version are shown in Table 1. However, if the analysis is repeated using the untransformed version of this scale, the results are similar. 
responses ranged from once to several hundred times. Because this scale was skewed, the data were transformed to create a more normally distributed dependent variable. In the transformation, all values over 7 were collapsed, creating a variable ranging from 0 to $7($ mean $=1.48$, standard deviation $=2.27) .{ }^{4}$

\section{The First Interview-Judgments About the Conference/Court Experience}

\section{Procedural Fairness of the Case Disposition Process}

Procedural fairness was assessed in three ways: by a nine-item scale indexing the fairness of the conference or court processing $($ mean $=3.56$, standard deviation $=0.64$, alpha $=0.87)$; by a fiveitem scale evaluating the fairness of the police (mean $=3.77$, standard deviation $=0.64$, alpha $=0.79$ ); and by a seven-item scale indexing the legitimacy of the legal system (mean $=4.32$, standard deviation $=0.50$, alpha $=0.75$ ).

The nine items used to measure procedural justice were: "How fair did you feel the conference/court was for you?"; "How much did you feel that the conference/court respected your rights?"; "People were polite to you in the conference/court"; "You felt you had an opportunity to express your views"; "All sides got a fair chance to bring out the facts in the conference/court"; "The conference/court took account of what you said in deciding what should be done"; "You feel you were treated with respect in the conference/court"; "How much influence did you have over the agreement?"; and "You felt you had enough control over the ways things were run in the conference/court."

The five items measuring police procedural fairness were: "The police were fair in the time leading up to the conference/ court"; "The police were fair during the conference/court"; "You felt you could trust the police during this case"; "In general, the police enforced the law fairly"; and "As a result of the way your case was handled would you say your respect for the police has gone up/ down?"

The seven-item legitimacy scale included these items: "If we all respected the law, the quality of our lives would be better"; "Obeying the law is the best way of making sure that our community is safe"; "In general, you have respect for the law"; "How wrong do you think it is to drive when you are over the legal alcohol limit?"; "How wrong is it to shoplift?"; and "How wrong is it to start a fight?" and "To hit someone who is not looking for trouble?"

4 The Time Two variable indexing self-reported frequency of driving while drunk was used as a dependent variable in the analysis reported later. It was therefore transformed to minimize its skewness. For consistency, the Time One measure of the same construct was also similarly transformed. 


\section{Reintegrative Shaming Items}

Measurement of reintegrative shaming largely followed the approach outlined by Ahmed and colleagues (2001). The model presented therein distinguishes among three aspects of reintegrative shaming: reintegration, stigmatization, and shaming. Impact of recidivism on social ties was also measured. Scales were created to measure reintegration $($ mean $=2.44$, standard deviation $=0.88$, alpha $=0.81)$, stigmatization $($ mean $=1.68$, standard deviation $=$ 0.65 , alpha $=0.76)$, shaming (mean $=3.05$, standard deviation $=0.69$, alpha $=0.86$ ), and believing that reoffending would create problems in one's social relationships (mean $=2.86$, standard deviation $=0.79$, alpha $=0.62$ ) .

Reintegration. A five-item scale was drawn from Ahmed and colleagues (2001). The items were: "Did you learn from the conference/court that there are people who care about you?"; "During the conference/court case did people talk about aspects of yourself that they like?"; "At the end of the conference/court case, did people indicate that you were forgiven?"; "Did others at the conference/court case say that you have learned your lesson and deserve a second chance?"; and "Did people in the conference/ court case say that it was not like you to do something wrong?"

Stigmatization. A four-item scale was drawn from Ahmed and colleagues (2001). The items were: "Were you treated in the conference/court case as though you were likely to commit another offence?"; "Did people during the conference/court case make negative judgments about what kind of a person you are?"; "During the conference/court case were you treated as though you were a criminal?"; and "During the conference/court case were you treated as though you were a bad person?"

Shaming. A seven-item shaming scale was created (alpha $=$ 0.87). The first four items asked these questions: "How ashamed were you... 'That your family found out about the offence you committed?'; 'That your friends found out about the offence you committed?'; 'That the police, the magistrate, or other government officials found out about the offence you committed?'; and 'That other people found out about the offence you committed (for example workmates, school mates, neighbors, etc.)?' The other three items were: "During the conference/court case I felt ashamed of what I did"; "During the conference/court case I felt ashamed of myself"; and "During the conference/court case I felt ashamed because people criticized me for what I had done."

Impact of recidivism on social ties. Three items assessed the degree to which offenders felt that rearrest would create problems in their social relationships: "If you were caught again how much of a problem would it be?"; "If you were caught for the same kind of 
offence again, how much of a problem would it create for you if your family and friends found out?"; and "If you were caught for drunk driving again, how much of a problem would it create for your life if your name and offence were printed in the newspaper?"

\section{The Second Interview}

During the second interview, offenders were asked about two general law-related attitudes. The first was the legitimacy and feelings of obligation they felt toward the law. The second was the degree to which they felt that breaking the law would create problems for them and for their family.

\section{Legitimacy}

Two items assessed offenders' views about their relationship to the law $($ mean $=4.09$, standard deviation $=0.80$, alpha $=0.74$ ): "The conference/court case will keep you from breaking the law in the future," and "What happened in the conference/court case will encourage you to obey the law in the future."

\section{Impact of Recidivism on Social Ties}

Four items assessed the degree to which offenders felt that rearrest would create problems in their social relationships ( mean $=3.33$, standard deviation $=0.58$, alpha $=0.62$ ): "If you were caught again how much of a problem would it be?"; "If you were caught for the same kind of offence again, how much of a problem would it create for you if your family and friends found out?"; "If you were caught for drunk driving again, how much of a problem would it create for your life if your name and offence were printed in the newspaper?"; and "If caught again, how tough would your punishment be?"

\section{References}

Ahmed, Eliza, et al. (2001) Shame Management through Reintegration. Cambridge, United Kingdom: Cambridge Univ. Press.

Allen, Francis A. (1981) The Decline of the Rehabilitative Ideal: Penal Policy and Social Purpose. New Haven, CT: Yale Univ. Press.

Anderson, Jill K., \& Robert M. Hayden (1980-81) "Questions of Validity and Drawing Conclusions from Simulation Studies in Procedural Justice," 15 Law E' Society Rev. 293-304.

Barnes, Geoffrey C. (1999) Procedural Justice in Two Contexts: Testing the Fairness of Diversionary Conferencing for Intoxicated Drivers. Ph.D. dissertation, Department of Criminology and Criminal Justice, University of Pennsylvania.

Bonta, James, et al. (2006) "Restorative Justice and Recidivism: Promises Made, Promises Kept?," in D. Sullivan \& L. Tifft, eds., Handbook of Restorative Justice: A Global Perspective. London: Routledge. 
Braithwaite, John (1989) Crime, Shame and Reintegration. Cambridge, United Kingdom: Cambridge Univ. Press.

(2002) Restorative Justice and Responsive Regulation. Oxford, United Kingdom: Oxford Univ. Press.

Braithwaite, Valerie (2003) Taxing Democracy: Understanding Tax Avoidance and Evasion. Aldershot, United Kingdom: Ashgate.

Cohen, Jacob, et al. (2003) Applied Multiple Regression/Correlation Analysis for the Behavior Sciences, 3d ed. Mahwah, NJ: Erlbaum.

Colquitt, Jason A., et al. (2001) "Justice at the Millennium: A Meta-Analytic Review of 25 Years of Organizational Justice Research," $86 \mathrm{~J}$. of Applied Psychology 425-45.

Hayden, Robert M. (1989) "Cultural Context and the Impact of Traffic Safety Legislation," 23 Law E' Society Rev. 283-94.

Johnstone, Gerry (2002) Restorative Justice: Ideas, Values, Debates. Portland, OR: Willan Publishing.

Latimer, Jeff, et al. (2005) "The Effectiveness of Restorative Justice Practices: A MetaAnalysis," 85 The Prison J. 127-44.

Luna, Erik (2003) "Introduction: The Utah Restorative Justice Conference," 2003 Utah Law Rev. 1-14.

MacCoun, Robert J. (1993) "Drugs and the Law: A Psychological Analysis of Drug Prohibition," 113 Psychological Bulletin 497-512.

Mugford, Stephen (2003) "The Butterfly's Wing, Bread Pudding and Justice: The Relevance of Complexity Theory to ADR Processes," 9 VCAT Mediation Newsletter 20-1.

Murphy, Kristina (2004) "The Role of Trust in Nurturing Compliance: A Study of Accused Tax Avoiders," 28 Law and Human Behavior 187-209.

Nagin, Daniel S. (1998) "Criminal Deterrence Research at the Outset of the Twenty-First Century," 23 Crime and Justice 1-42.

Nugent, William R., et al. (2003) "Participation in Victim-Offender Mediation and the Prevalence and Severity of Subsequent Delinquent Behavior: A Meta-Analysis," 2003 Utah Law Rev. 137-66.

Paternoster, Raymond, et al. (1997) "Do Fair Procedures Matter? The Effects of Procedural Justice on Spouse Assault," 31 Law E' Society Rev. 163-203.

Poulson, Barton (2003) "A Third Voice: A Review of Empirical Research on the Psychological Outcomes of Restorative Justice," 2003 Utah Law Rev. 167-203.

Pruitt, Dean G., et al. (1993) "Long-Term Success in Mediation," 17 Law and Human Behavior 313-30.

Roberts, Julian V., \& Loretta J. Stalans (2004) "Restorative Sentencing: Exploring the Views of the Public," 17 Social Justice Research 315-34.

Robinson, Paul, \& John Darley (1995) Justice, Liability, and Blame. Boulder, CO: Westview. —_ (1997) "The Utility of Desert," 91 Northwestern University Law Rev. 453-99.

Roche, Declan (2003) Accountability in Restorative Justice. Oxford, United Kingdom: Oxford Univ. Press.

Sherman, Lawrence W. (1993) "Defiance, Deterrence and Irrelevance: A Theory of the Criminal Sanction," $30 \mathrm{~J}$. of Research in Crime and Delinquency 445-73.

Sherman, Lawrence W., \& Heather Strang (2004) "Verdicts or Inventions? Interpreting Results from Randomized Controlled Experiments in Criminology," 47 American Behavioral Scientist 575-607.

Sherman, Lawrence W., et al. (2000) Recidivism Patterns in the Canberra Reintegrative Shaming Experiments. Canberra: Australian National University, RSSS, Centre for Restorative Justice.

Strang, Heather (2002) Repair or Revenge: Victims and Restorative Justice. Oxford, United Kingdom: Oxford Univ. Press.

Strang, Heather, \& John Braithwaite (2000) Restorative Justice. Aldershot, United Kingdom: Ashgate. 
Strang, Heather, \& Lawrence W. Sherman (2006) "Restorative Justice to Reduce Victimization," in B. C. Walsh \& D. P. Farrington, eds., Preventing Crime: What Works for Children, Offenders, Victims and Places. Dordrecht, The Netherlands: Springer.

Sullivan, Dennis, \& Larry Tifft (2001) Restorative Justice: Healing the Foundations of Our Everyday Lives. Monsey, NY: Willow Tree Press.

Sunshine, Jason, \& Tom R. Tyler (2003) "The Role of Procedural Justice and Legitimacy in Shaping Public Support for Policing," 37 Law E Society Rev. 513-47.

Thibaut, John, \& Laurens Walker (1975) Procedural Justice. Mahwah, NJ: Erlbaum.

Travis, Jeremy (2004) But They All Come Back: Facing the Challenges of Prison Reentry. Washington, DC: Urban Institute Press.

Tyler, Tom R. (1988) "What Is Procedural Justice? Criteria Used by Citizens to Assess the Fairness of Legal Procedures," 22 Law \& Society Rev. 103-35.

_ (2000) "Social Justice: Outcome and Procedure," 35 Intermational J. of Psychology $117-25$.

- (2003) "Procedural Justice, Legitimacy, and the Effective Rule of Law," 30 Crime and Justice 283-357.

- (2006a) Why People Obey the Law. Princeton, NJ: Princeton Univ. Press.

(2006b) "Legitimacy and Legitimation," 57 Annual Rev. of Psychology 375-400.

Tyler, Tom R., \& Yuen J. Huo (2002) Trust in the Law. New York: Russell Sage.

Tyler, Tom R., \& E. Allan Lind (1992) "A Relational Model of Authority in Groups," 25 Advances in Experimental Social Psychology 115-91.

Von Hirsch, Andrew, et al. (2003) Restorative Justice and Criminal Justice: Competing or Reconcilable Paradigms? Oxford, United Kingdom: Hart Publishing.

Weitekamp, Elmar G. M., \& Hans-Jurgen Kerner (2002) Restorative Justice: Theoretical Foundations. Portland, OR: Willan Publishing.

Tom R. Tyler is a University Professor at New York University. He teaches in the psychology department and the law school. His research explores the dynamics of authority in groups, organizations, and societies. In particular, he examines the role of judgments about the justice or injustice of group procedures in shaping legitimacy, compliance, and cooperative behavior.

Lawrence W. Sherman is the Director of the Jerry Lee Center of Criminology at the University of Pennsylvania and the scientific director of the Reintegrative Shaming Experiments (RISE) at the Australian National University's Research School of Social Sciences. He has designed and directed randomized controlled field experiments on the use of arrest for domestic violence, police patrols of crime hot spots, police raids of drugdealing houses, and other crime control strategies. He is currently working on eight randomized trials of restorative justice within the criminal justice system in the United Kingdom.

Heather Strang is Director of the Centre for Restorative Justice at the Research School of Social Sciences, Australian 
National University. Since 1995, she has been managing studies investigating the effectiveness of restorative justice in Australia and the United Kingdom. She has a special interest in victims of crime, which is the focus of her own research. Her book, Repair or Revenge: Victims and Restorative Justice, was published in 2002 (Oxford, United Kingdom: Clarendon Press).

Geoffrey C. Barnes is a research associate in the Jerry Lee Program on Randomized Controlled Trials in Restorative Justice at the Jerry Lee Center of Criminology.

Daniel Woods is a Ph.D. candidate in criminology at the University of Pennsylvania and a research associate in the Jerry Lee Program on Randomized Controlled Trials in Restorative Justice at the Jerry Lee Center of Criminology. 